\title{
Radical transparency: Open access as a key concept in wiki pedagogy
}

\author{
Rolf K. Baltzersen \\ Østfold University College
}

\begin{abstract}
Educators have just started to use wikis and most of the educational research to date has focused primarily on the use of local wikis with access limitations. There seems to be little research related to how students can contribute in global, transparent wiki communities such as Wikipedia and Wikibooks. The purpose of this article is to argue that we need to extend our understanding of transparency as a pedagogical concept if we want to use these open, global wiki communities in an educational setting. By describing one wiki based course in detail, I argue that these kinds of radically transparent learning environments in tertiary education challenge traditional pedagogy and our ordinary perceptions of what a class and working assignment is. The course data in this article include a course description and teacher and student reflections on assessed group projects which produced "student written, collaboratively edited textbooks" on Wikibooks. Student perceptions indicate positive attitudes towards global learning environments, if the didactical design is carefully planned. In the article I suggest that "outsiders" and "former and future students" should be included as categories in a pedagogical definition of transparency. These categories represent a radical expansion of course space and course availability.
\end{abstract}

\section{Introduction}

\section{Web 2.0 and the new transparent learning environments}

"Web 2.0" is often associated with web development that facilitates interactive information sharing, user-centered design and collaboration. All these new tools and technologies include file sharing communities, web applications, social networking sites, video sharing sites, blogs and wikis. File sharing websites such as Flickr (photo sharing) and YouTube (video sharing) provide millions of users with personal spaces where they can store documents, pictures or videos and share them with other users. Although Web 2.0 suggests a new version of the world wide web, it does not refer to any technical specification, but rather to changes in the ways people use the web (O`Reilly, 2005).

It's now easy for anyone to publish whatever they like to present. Ordinary people are now sharing information openly in ways we have not experienced before (Benkler, 2006; Kolbitsch \& Maurer, 2006; Murugesan, 2007). From a practical perspective, Web 2.0 is characterised by most or all of the following activities (Dohn, 2009):

- collaboration and/or distributed authorship

- active, open access, "bottom up" participation and interactive multi-way communication 
- continuous production, reproduction, and transformation of material in use and reuse across contexts

- openness of content, renunciation of copyright, distributed ownership

- lack of finality, "awareness in practice" of the "open endedness" of the activity

- taking place on the WWW, or to a large extent utilising web-mediated resources and activities

Being "Web 2.0" is here rather a question of degree. Specific activities may possess some or all of these factors, and each factor will possess the characteristic to a greater or lesser extent.

In recent years we have also seen an increased interest in using Web 2.0 technologies in education. This new technology makes it possible for students to communicate with each other in new ways, they can become creative producers of media and express their own opinions in new public areas (Buckingham, 2007; Owen, Grant, Sayers \& Facer, 2006; Ravenscroft, 2009; Richardson, 2009). The Web 2.0 technologies move beyond traditional learning management systems and can support self-governed, problem based and collaborative activities in a better way (Alexander, 2006; Dalsgaard \& Paulsen, 2009).

In this article I will focus especially on transparency issues related to education. Basically, the definition of transparency is quite simple. It means being open, frank or candid. The term has become a buzzword not only in business settings, but also in government and the social sector as well (Bennis, Goleman, O'Toole \& Biederman, 2008).

In a democratic society transparency is connected to the citizen's right to be informed and have access to information about political processes. This may for instance include public access to policy documents. Cuiller and Piotrowski (2009), for example, discuss whether online information-seeking increases support for government transparency. Public access to government records is looked upon as essential for democratic selfgovernance (Cuillier \& Piotrowski, 2009). Recently, transparency has also been linked to Open Government ('Gov 2.0' movement) strategies and the push to free up more public information (Lathrop \& Ruma, 2010).

Nevertheless, since total transparency never will be fully obtainable, one could speak of "the politics of transparency". The important question is which information should be made public, to what extent, and when this should be done (Garsten \& Montoya, 2008). "Targeted transparency", for example, refers to the mandated public disclosure of information by organisations regarding specific products or practices. This is different from traditional transparency processes where the information seeker has to invest time to figure out where the required information might be obtained (Fung, Graham \& Weil, 2007).

In an organisation transparency is often related to the free flow of information within the organisation itself and between the organisation and its many stakeholders. This "information flow" is of enormous value. The central idea is that if people behave rationally, improving the quantity and/or quality of information is likely to result in better decisions. According to the authors, the best way to strengthen transparency is by welcoming unpleasant information (Bennis et al., 2008). 
An organisation may of course have a legitimate interest in holding back information about innovations or corporate strategies. In traditional public relations management, damage control also usually involves the suppression of public information. Nevertheless, according to Tapscott (2003) this strategy is not recommendable today. Since Internet commentary is inescapable, the only way to influence it is to be part of it. Being transparent and even publishing unpleasant information is the best way to build up your reputation (Tapscott \& Ticoll, 2003)

The term transparency is also related to the Open Access movement. Open access (OA) describes the public's unrestricted online access to articles published in scholarly journals while Open Educational Resources (OER) are learning materials that are freely available for use, remixing and redistribution. This movement may open new channels for the flow of knowledge.

In recent years the term "radical transparency" has also been used to describe an openness where ideally as many processes as possible are carried out publicly. Daniel Goleman (2010), for instance, writes about the age of radical transparency. He discusses the potential for "new technologies" to reveal the eco-impact of products we buy. Transparency is seen upon as a new management approach where information about the production processes is easily accessible for consumers. With this information consumers can make smarter decisions and companies can reform their business practices as "the control of data shifts from sellers to buyers" (Goleman, 2010).

Another example is the development of the social networking service Facebook. David Kirkpatrick (2010) suggests that Facebook is founded on a radical social premise - that an inevitable transparency will overtake modern life. Facebook is causing a mass resetting of the boundaries of personal intimacy with a large number of users filling out extensive details about their career, relationships, interests and personal history. Mark Zuckerberg, the founder of Facebook, believes that people will be better off if they make themselves transparent in this way. More transparency can create a more tolerant society in which people eventually accept that everybody sometimes does bad or embarrassing things. Since the world is likely to become more and more open anyway, people might as well get used to it. This idea is related to a concept which they in the company call either "ultimate transparency" or "radical transparency" (Kirkpatrick, 2010).

In an educational context, transparency is often related to school improvement through enhancing the availability or visibility of information. Hansen (2008), for instance describes the availability of education data in California. Furthermore, she discusses the potential for using these data to support school improvement efforts (Hansen, 2008). In a school context transparency is also often associated with the term accountability (Kelly \& Aldeman, 2010). Transparency on an institutional level may for example be related to citizens expecting access to more information about the local school district ((LaFee, 2009). There are also researchers emphasising the importance of transparent learning activities in the classroom. It is, for example, suggested that a more transparent assessment can greatly improve the students' performances (Jonsson, 2010).

Another example is Dalsgaard and Paulsen (2009) who claim that the pedagogical potential of social networking lies primarily within transparency and the ability to create awareness among students. Transparency is here defined as having insight into 
each other's activities and resources. This implies that educational activities are visible to all students and teachers within a learning environment. For instance, transparency could mean that students and teachers are made aware of and have access to each other's interests, thoughts, concerns, ideas, writings, references, and assignments. They claim that the purpose of transparency in an educational context is to enable students and teachers to see each other's work and in that sense make it available as a resource for their learning activities.

Transparency can improve quality in three different ways. Firstly, we may want to provide better quality when we know that others have access to the information and contributions we provide. Secondly, we may learn from others when we have access to their data and contributions. Thirdly, we may receive feedback from others when they have access to our work. However, students engaged in individual or group work in traditional courses are not aware of the activities of the other students within a course.

Rudd, Sutch and Facer (2006) argue that we need to move away from the institutionalised logic of the school as factory, to the "network logic" of the learning community. A range of social software tools also offer the potential for collaboration in building learning networks, not just with people from the immediate community, but also with others from a much wider geographical and demographic 'pool'. We therefore need to rethink the possibilities around what can be learnt, where learning can happen and who is involved in the learning process. We have to challenge the assumption that expertise and knowledge reside only within the walls of the educational institution. We should develop a system organised through more flexible learning networks that link homes, communities and multiple sites of learning in an easy and cost effective way.

The ability to understand how to join and build these networks, the tools for doing so and the purpose, intention, rules and protocols that regulate use and communications, therefore become increasingly important skills. This concept of the "network society" calls into question what it means to be 'educated' today - what new skills, what new ways of working and learning, what new knowledge and skills will be required to operate in and through these networks? It requires us to ask whether our current education system, premised not upon networks but upon individualised acquisition of content and skills, is likely to support the development.

According to Scardamalia and Bereiter (2006), the Internet becomes the first realistic means for students to connect with civilisation-wide knowledge building and to make their classroom work a part of it. They find that young students are delighted to see their inquiry connect with that of learned others, past or present. The driving force is not so much the individual interests of children as their desire to connect with what is most dynamic and meaningful in the surrounding society. From this standpoint the fundamental task of education is to initiate students into a knowledge creating culture, and to help them find a place in it. In light of this challenge, both traditional educational practice and newer constructivist methods appear to be limited in scope. Students should not only develop knowledge-building competencies, but also come to see themselves and their work as part of the civilisation-wide effort to advance knowledge frontiers.

A motive guiding their research has been a belief that students themselves represent a resource that is largely wasted and that could be brought into play through network technology. 


\section{Educational use of wikis}

Wikis are looked upon as one of the most interesting Web 2.0 technologies. They can be used for a multitude of purposes also in education. Whereas file sharing systems are used to contain and share information, wikis have special potential for collaborative knowledge building. Wikis were first introduced by Ward Cunningham in the middle of the 1990s, as a tool to support fast and easy text collaboration over the Internet. Their special feature is that one can very easily add, delete or change any part of the published text. All the different text versions are stored making it possible to retrieve an old text version (Leuf \& Cunningham, 2001). The multilingual, web based encyclopedia Wikipedia represents the prime example of the collaborative potential in the wiki. The quality is remarkably high even though anyone can contribute and change articles (Giles, 2005).

Research on educational use of wikis has increased in recent years. The theoretical perspectives vary, but overall, wikis are considered to be especially good in facilitating social constructivist learning processes (Bruns \& Humphreys, 2005; Lund, 2008; Ruth \& Houghton, 2009). Research has also been done on how wikis can support constructivist learning processes (Heafner \& Friedman, 2008; Parker \& Chao, 2007). Wikis can both support inquiry learning (Yukawa, 2006) and the use of deep levels of cognition (Aharony, 2009; Karimi \& Song, 2009; Matthew \& Felvegi, 2009; Matthew, Felvegi \& Callaway, 2009). It is also claimed that they challenge traditional pedagogical assumptions about the teaching of writing (Lundin, 2008) by facilitating both revision writing (Ma \& Yuen, 2008) and authentic writing (Forte \& Bruckman, 2006; Mak \& Coniam, 2008). One critical didactical issue concerns the teacher's difficulty in evaluating the students' individual contribution in group work (Elgort, Smith, \& Toland, 2008; Trentin, 2009). There is also a growing interest in the wiki's potential in connecting professionals (Johnson, Shelton \& Wiley, 2008; Sheehy, 2008) and supporting the development of student-created content (Wheeler, Yeomans \& Wheeler, 2008).

Some researchers also emphasise the importance of transparency in the wikis. Zorko (2009) recommends that all the group's work in a wiki should be visible and easily accessible. In this way the students will be able to learn from each other by comparing each other's products. They will also be able to read and follow the advice the teachers give to the other groups. Knowing that other people will read their work will in addition make the students more motivated to do their best.

Still, we need to better understand the underpinning epistemology required to build content and communities in a wiki (Ruth \& Houghton, 2009). There is still a lack of research that investigates the pedagogical potentials of wikis for collaborative learning (Elgort et al., 2008). Some research also indicates that collaborative writing and learning is more the exception than the norm (Lin \& Kelsey, 2009). This is thus challenging idealistic hypotheses that wikis are natural beneficial. There is even less research on the educational use of global wiki communities such as Wikipedia and Wikibooks. Empirical studies usually focus on how Wikipedians work (Bryant, Forte \& Bruckman, 2005; Hoisl, Aigner \& Miksch, 2007). The limited research that has been done here is also mainly prescriptive (Konieczny, 2007; Staley, 2009). Still, some empirical textbook projects have been done in relation to the educational use of wikis as textbooks (O'Shea, Baker \& Kidd, 2008; Ravid, Kalman, \& Rafaeli, 2008), but none have been found related to the educational use of global wiki communities. 


\section{The textbook project}

\section{The course}

Every spring semester Østfold University College in Norway offers a course in "Pedagogical (educational) use of ICT". The course is part of a bachelor degree program at the Faculty of Education. Both pre-service and in-service teacher students can take the course as a part time study (ECTS 15 credits). The main objective is to develop students' digital competency (digital literacy) and strengthen their ability to use ICT in education. The learning environment is blended and offers a combination of face to face workshops and web-based work assignments.

The course has received both practical and academic interest because of all the Web 2.0 applications that are part of the digital learning environment. For example, Nordkvelle (2007) acknowledges the pedagogical thinking in the course as part of a pioneering work in Norwegian higher education. Instead of a traditional learning management system, a class blog is used to distribute information. In addition, all the student work is published through open Web 2.0 channels such as YouTube and Wikibooks (http:/ / iktforlaerere.blogspot.com/).

Students are required to complete several assignments during the course. In 2009 they had to make a digital story, do two textbook assignments in a wiki and write five individual blog comments in the class blog. This work was compulsory and the first three assignments were done in groups comprising two or three students. In sum, these three assignments counted 30\% of the final grade. In addition there was a final oral exam counting $70 \%$ of the grade, In the oral exam the students had to reflect on their work with the assignments. In addition, they had to present their understanding of different content in the syllabus (readings).

The two wiki assignments are part of a textbook project where students are supposed to develop a student written, collaboratively edited textbook about ICT in education. The Wikipedian community (not the wiki) was a part of the inspiration behind the textbook project in this study (Baltzersen \& Tolsby, 2008). The idea was to create a formal learning environment based on the informal learning culture in Wikipedia. The textbook is therefore published on an open wiki site called Wikibooks (some of the articles have also been published in Wikipedia). Wikibooks is a site where volunteers are creating a free library of educational textbooks. Since 2003 the English version has grown to include over 38,480 pages (http://en.wikibooks.org/wiki/Main_Page). As is the case with Wikipedia, anyone can contribute. The main difference is that there is far less activity on Wikibooks, though it also requires administrators to counter vandalism.

The textbook itself contains both practical resources and academic articles (http:// no.wikibooks.org/wiki/IKT_i_utdanning). The project started in 2008, and the class of 2009 has continued to improve the textbook. The first year the teacher made a tentative textbook structure and gave some examples on how to write an article. In this way students could more easily understand what they were supposed to do.

One of the wiki assignments in 2009 was a revision task. Student groups had to edit and improve concrete articles that the 2008 class had been working with. In this way they did not start writing the text from scratch, but they had to improve and continue the work of former students. They were required to improve the hypertext by finding new relevant links, add more relevant pictures, extend the use of high quality sources 
by adding more academic literature and improve the text by removing irrelevant content (some groups even ended up with a shorter article). In the other wiki assignment students had to develop subject specific repositories related to objectives in the national curriculum. They had to find relevant links to different types of multimodal material on the web and present them in an informative way in the textbook.

Some parts of the textbook were also included in the syllabus (course readings). This was done to ensure that the textbook was given high priority in the course. All the students therefore had to read each other's articles before the oral exam. The teacher also had to ascertain that the quality of the content was good enough.

\section{A transparency matrix for student work in wiki environments}

What kind of transparency is it possible to locate in global wiki learning environments? As a point of departure, it can be relevant to use a transparency matrix for online courses (Dalsgaard \& Paulsen, 2009). They present the following categories in the matrix: "Student", "Teacher", "Students in class" and "Students in other classes". These four categories seem functional for transparency issues within a closed learning environment such as an ordinary learning management system. On the other hand they don't seem to be sufficient when students are participating and working in open, global wiki environments.

The top row in the matrix below (Table 1) describes who has participated in the wiki learning activities in the course. The category "Outsiders" is here introduced to describe persons who have participated in the course without formally being a student at the institution. This may be students from other institutions or other non-students who are interested in the topic. These persons represent a new spatial expansion of the ordinary classroom that the Internet enables. As Rudd, Sutch and Facer (2006) noted earlier, new social software offer the potential for collaboration outside the walls of the traditional educational institution. This is why they claim we need to rethink the possibilities where learning can happen and who is involved in the learning process. As a consequence of this, "Outsiders" is here suggested as a relevant category that can fill this expansion of the spatial dimension.

The new category "Former and future students" is based on an important feature with a global wiki community. The wiki text will be available both before and after the course. In this way new students can prepare themselves for the course before it formally begins, by studying the course's wiki pages. Former students can continue to work with the wiki assignments also after the course is over. The assignment extends the traditional time limit for a course activity because it is possible to continue to use and modify text material from the course. This activity is similar to part of Dohns (2010) definition of Web 2.0 which is characterised by continuous production and reproduction of digital content. As mentioned before, Scardamalia and Bereiter (2006) also find that young students are delighted to see their inquiry connect with that of learned others, past or present.

The column at the far left of Table 1 illustrates several possible wiki learning activities. Work with both draft versions and the final products are included in the column. In addition a distinction is made between just reading and actually changing student text. The matrix describes only a part of the complexity concerning transparency issues in a wiki learning environment. 
Table 1: A revised transparency matrix for student work in wiki learning environments

\begin{tabular}{|l|c|c|c|c|c|c|}
\hline \multicolumn{1}{|c|}{ Student work } & $\begin{array}{c}\text { Student } \\
\text { (you) }\end{array}$ & Teacher & $\begin{array}{c}\text { Students } \\
\text { in class }\end{array}$ & $\begin{array}{c}\text { Students } \\
\text { in other } \\
\text { classes }\end{array}$ & $\begin{array}{c}\text { Out- } \\
\text { siders }\end{array}$ & $\begin{array}{c}\text { Former and } \\
\text { future } \\
\text { students }\end{array}$ \\
\hline Read student text & $\mathrm{X}$ & $\mathrm{X}$ & $\mathrm{X}$ & $\mathrm{X}$ & $\mathrm{X}$ & $\mathrm{X}$ \\
\hline Change student text & $\mathrm{X}$ & $\mathrm{X}$ & $\mathrm{X}$ & $\mathrm{X}$ & $\mathrm{X}$ & $\mathrm{X}$ \\
\hline Read draft versions of student text & $\mathrm{X}$ & $\mathrm{X}$ & $\mathrm{X}$ & $\mathrm{X}$ & $\mathrm{X}$ & $\mathrm{X}$ \\
\hline Change draft versions student text & $\mathrm{X}$ & $\mathrm{X}$ & $\mathrm{X}$ & $\mathrm{X}$ & $\mathrm{X}$ & $\mathrm{X}$ \\
\hline $\begin{array}{l}\text { Read student reflection about wiki } \\
\text { assignment }\end{array}$ & $\mathrm{X}$ & $\mathrm{X}$ & $\mathrm{X}$ & $\mathrm{X}$ & $\mathrm{X}$ & $\mathrm{X}$ \\
\hline $\begin{array}{l}\text { Comment on student reflection } \\
\text { about wiki assignment }\end{array}$ & $\mathrm{X}$ & $\mathrm{X}$ & $\mathrm{X}$ & $\mathrm{X}$ & $\mathrm{X}$ & $\mathrm{X}$ \\
\hline $\begin{array}{l}\text { Read teacher feedback on student } \\
\text { text }\end{array}$ & $\mathrm{X}$ & $\mathrm{X}$ & $(\mathrm{X})$ & $(\mathrm{X})$ & $(\mathrm{X})$ & $(\mathrm{X})$ \\
\hline $\begin{array}{l}\text { Read formal assessement } \\
\text { Undo vandalism }\end{array}$ & $\mathrm{X}$ & $\mathrm{X}$ & & & & \\
\hline
\end{tabular}

The matrix tries to give an overview of central transparency dimensions in a course based on student participation and work in a global wiki environment. The two columns on the right represent the radical transparent dimension in the course. Here we find the categories "Outsiders" and "Former and future students". It is through these categories that the radical transparent dimension enters the wiki learning environment.

The " $X$ " in the matrix indicates who has participated in the different wiki learning activities in this course. The number of " $\mathrm{Xs}^{\text {" }}$ in the matrix describes the total intended transparency. In this specific case the "Xs" show that the students' work with the wiki assignment was not totally transparent. This is not necessarily either an ideal. Teacher feedback was for instance only published on the wiki discussion page when student text products had been assessed as acceptable. Very critical comments from the teacher were instead sent privately to the student. The parenthesis around the $X$ indicates that only some of the teacher feedback was published openly.

It is also difficult to pinpoint the actual level of transparency in the students' work. For example, we don't know how many students or outsiders have read a student's text, but we know that the amount of text revisions done by outsiders has been limited.

The matrix is tentative and it will need further development, but it is suggested that it can function as a framework for discussing pedagogical implications of transparency. It is meant to be a tool which can be used to reflect on how transparent a wiki course actually is. Primarily in this paper I discuss issues related to the two columns on thr right of the matrix (Table 1). Using a course in teacher education as background material, I try to describe possible pedagogical advantages and disadvantages of radical transparency in wiki based learning environments.

\section{Data collection}

The empirical research question is: "How do students experience working in open (transparent) global wiki communities?" Wiki environments such as Wikibooks and Wikipedia differ from local wikis because of the global transparency and openness. In this paper I will discuss how students experience working with a wiki textbook in a global learning community. The empirical material is based on student reflections 
working with the two wiki assignments previously mentioned. Only data from the class of 2009 has be used for this paper.

Twenty-one students participated in the course in 2009. A survey that was done before the students started the course shows that a majority used computers several hours a day in their leisure time. This indicates that the student cohort enjoys using computers. Course admission also requires students to pass an exam in basic computer skills. It is therefore likely that the students in this material have fewer problems learning to use new digital tools than other students. Most of the students were pre-service teacher students, with a few students already working as teachers. Two types of student data were collected in this study. Both are based on how these students experienced the wiki activities in the course.

Firstly, as one of the obligatory assignments in the course, students had to write five blog posts each about different topics in the course. It was a minimum requirement that one of these blog posts should reflect how they experienced working with the wiki assignments. A total of 28 blog posts were written with 7 students writing two posts about the wiki textbook. The students were not anonymous when they wrote in the blog. Other students were also supposed to read and comment on the blog postings. A total of 37 comments were added to the 28 blog posts about the wiki assignments. The blog assignment was not graded.

Secondly, an online survey was conducted immediately after the course concluded, approximately one month before the final oral exam. 10 of 21 students answered voluntarily on an anonymous questionnaire with open ended questions. The survey was designed to elicit additional comments from the students regarding their participation in the wiki, and to confirm information found in the reflections. Students were asked about how they experienced publishing their end products in transparent learning environments. They were also asked specifically about how they liked working with the revision task and making a new resource page in the textbook. The survey was an important supplement to the blog, because the students could be anonymous.

The open text responses provided by students suggest an overall positive reaction to the assignments, including the blog posts and the online survey. None of the students were directly dissatisfied with the wiki work. This is also confirmed by a high average course satisfaction score ( 4.5 points on a scale from one to five with five being the top score).

All the empirical content related to the two transparency categories "Outsiders" and "Former and future students" has been included in the analysis. Examples used in this paper have been selected on the basis of their complexity. The aim of this approach has been to enrich a discussion of educational implications with reflections around both advantages and disadvantages. All the quotations are translated from Norwegian to English.

\section{Discussion: Pedagogical implications of student participation in a radically transparent learning environment}

This section discusses pedagogical implications of working in a radically transparent wiki environment. It is related to the two categories in the matrix representing radical 
transparency, "Outsiders" and "Former and future students". By analysing student reflections on how they experienced working in a totally open wiki, I discuss possible pedagogical advantages and disadvantages of radical transparency.

\section{Pedagogical implications of extending course space}

From a pedagogical perspective, public access to student work is important because it may increase the motivation for delivering work with high quality (Dalsgaard \& Paulsen, 2009). Interestingly, none of the students resisted publishing their own final work openly. The student survey also indicated the same tendency with none of the students identifying this as problematic. One reason may be that "digital natives" are more used to operating openly on the internet. Another influencing factor may have been that the teacher used some time before the project started, to discuss the pedagogical importance of open publishing. Some students may, though, have had to overcome a fear that their work would not be good enough for a wider audience.

It may also have been easier for the 2009 class to publish their work openly, because it was done in groups and all the contributors except one group chose to be anonymous. A possible disadvantage of anonymity may be that it weakens student ownership. Still, several of the anonymous student groups were fascinated by their own participation in a global learning community through the course. One student for example wrote:

I think the concept with Wikibooks is exciting, as it is a source of knowledge that everybody can influence on and improve. It's exciting to see one's own article being out there, and that others have the opportunity to improve it ... (Source: blog post, all quotes are the author's translations from the original Norwegian).

The formulation "one's own article" indicates that the student feels ownership of the article, despite being anonymous. Similarly, other research shows that when students know that the quality and the usefulness of the wiki depends on them, they take ownership of the wiki. As one student in Matthew et al. (2009:63) reflected, "When you work hard on something and collaborate with others you want to see how it progresses and changes, and I know I want to see how others add to this project.". Knowing that someone else will try to improve their own work seems to strengthen a feeling of doing something that is of value.

The awareness of others potentially changing their contribution also seems to have a positive influence. Lin and Kelsey (2009) also obtained similar findings, as one student in their study wrote:

I found it very motivating mainly because other people were going to have the opportunity to see and edit my work. With traditional assignments you feel like you are doing the work for the teacher; however, wiki projects let me do the work for my peers, which in my case was very motivating (ibid: 162).

According to Augar, Raitman and Zhou (2004), sharing of authority is central to a wiki epistemology, but in the course in this case study the sharing involved not only the students, but also the authority of potentially interested wiki contributors from the Internet outside the class. There are no admission limitations in net communities such as Wikibooks and Wikipedia. When students contribute here, they have to accept the transparent rules of knowledge sharing that exist in these environments. In this way the textbook project challenges our ordinary conception of who can participate in classroom activities. As a principle, anyone can participate in the project at any time. 
Still, there have been very few external contributions during the research period in the project (spring 2009). An administrator removed some attempts on vandalism, some spelling corrections were done, and one encouraging comment was given.

External contributions may increase the students' feelings of participation in a global project with societal importance. A student expressed the same excitement about being outside the ordinary classroom walls:

\begin{abstract}
It was very instructive and some fun changing academic information that was already out there on the net, and then again publishing our final result. It's exciting to know that others might read and use something of it:) It's very good that pages like Wikibooks are out there and available for everybody because there are many important topics there. The assignment was very interesting and we learned a lot. As I said it was a little strange to change something already being out there, but it`s also very exciting to know that others might use what we have written. I hope it helps others as it helped us :) (Source: comment to a blog post).
\end{abstract}

There seems to be pride evident in the expressed excitement about someone potentially changing their own work. The formulation "I hope it helps others as it helped us" indicates the feeling that this is a worthwhile authentic learning activity. Lin and Kelsey (2009:162) also have similar findings in their study, as one student wrote: "I hope that my wiki chapters will help others. I think this is a great project and one that I would like to add to my online classes that I teach." Likewise, Matthew et al. (2009:64) gives examples of students telling students in other classes about their creation of a wiki: "I have told others about the wiki pages we worked on for our class and everyone thinks it [is] amazing that we were able to do it." Interestingly, several students in the textbook project wrote that they also experienced the work of their classmates as a valuable resource for them all. This is consistent with other studies showing that students take pride and ownership in their work and develop an appreciation of the contributions of the other users (Augar et al., 2004; Matthew et al., 2009).

One student recognised that the textbook project could be beneficial for all the teachers in school, when she wrote:

This was an instructive and fun assignment. I have worked as a teacher for many years and I can clearly see the potential in developing these kinds of repositories for the school. The second assignment was concrete and relevant. It would save teachers a lot of extra work if one could collaborate on making wikis in different subjects. All the teams at our school could be part of a useful learning process doing this kind of voluntary work ... (Source: blog post).

The student here emphasises the benefits of developing a better culture of sharing in the school. Building a good repository of learning resources is a very difficult task because of the enormous amount of information on the Internet. A few persons will not be able to manage it. Collaboration is therefore necessary. Interestingly, the student here through the course has developed an understanding of voluntary work as an important way of contributing. The student work is here looked upon as valuable for both course assessment and the teaching profession as a whole. The student seems to realise that the wiki can be beneficial to her learning and future teaching. Other research also confirms that students come to recognise their own work as important for others when they are working with a wiki (Matthew et al., 2009). 
In addition, the work in a transparent wiki environment seems to increase the awareness of the importance of critical literacy skills. A student emphasised that the wiki assignments make students themselves take responsibility for the information on the net:

The Wiki-family has not exactly had a rumour for publishing reliable and entrusted information, so I think it's okay to be able to say that I can vouch for these pages and this chapter being used in school. This assignment is very interesting because we take part in editing what others can use on the Internet. In a way we take some responsibility for the stream of information that we find on the Internet. In addition we focus on what we think is important or relevant and in that way influence the readers (Source: blog post).

Critical literacy becomes more important when students to a larger degree are operating outside the traditional course environment with a lot of different sources and persons. Through the wiki work the students also experience the text as dynamic with the possibility of making their own contributions. The new producer role also seems to potentially change the students' understanding of their responsibility for the information on the Internet. The student now seems to be more aware of the Internet as a place being used for advocating perspectives that different people think are important. He must bear witness to the content on the Internet that will be used in classroom lessons.

\title{
Pedagogical implications of extending course availability
}

The course in this case study operates with a different time frame than a traditional course. Firstly, new students are supposed to continue to improve the textbook every year. In the material several of the students acknowledge the practical value of working this way. They realise that it is not necessary to do the same work over and over again. One student in our course reflected about this issue in the following way:

\begin{abstract}
Working with Wikibooks in this course has been a new experience for me. The work has been both demanding and instructive. The wiki concept is in itself interesting since many can contribute with the improvement and the development of the pages. Our first assignment was to improve the article about "cyberbullying" ... However, we soon realised that we couldn't finish the article completely. It was too comprehensive and the time was too short, but I hope we have done a significant improvement. In any case it was quite peculiar to sit there and poke on other's work, but then again others will critically examine our work. This is how the concept works (Source: blog post).
\end{abstract}

The student here emphasises that they haven't finished the article, but they have done a significant improvement. This view of knowledge development is very similar to Scardamalia and Bereiter's (2006) pedagogical principle of "idea improvement". Students are here supposed to develop an understanding of knowledge as something being in constant change, adopting the working premise that all ideas are improvable. Ideally a student cohort should be able to pick up a thread of inquiry at a later time, even years later. This recognition of a never ending knowledge production process is also looked upon as a central feature in wiki pedagogy. For instance Ruth and Houghton (2009) relate wiki pedagogy to the notion of "epistemic authenticity", a concept developed by Nystrand (1997). If there are "prespecified" answers to questions, this will inhibit deep engagement by the students. In the same way the quoted student above sees his own work as part of a historical construction of the concept of "cyberbullying". By acknowledging that others again will continue to 
improve his own work, the student also includes an aspect of the future that goes beyond the ordinary course time frame. The students will here need the competency to position their work in relation to the work of others much in the same way as researchers. These collaborative learning processes are similar to a research orientated view of student learning (Scardamalia \& Bereiter, 2006). Researchers also build upon each other's knowledge through production of articles much in the same way as new classes in the textbook project build upon what former classes have done (research based methods). The textbook project requires students also to integrate new educational knowledge in a systematic way. In this way students seem to experience the learning processes as more authentic.

Another interesting paradox with wiki work is that it may be easier to continue the work with an article if the quality is low. One student wrote:

$$
\begin{aligned}
& \text { It was a totally new experience working with and editing Wikibooks. It was unfamiliar } \\
& \text { to correct something that others had written ... It was very obvious that those who } \\
& \text { had written before us had a big "text production" requirement, because there was too } \\
& \text { much information in the text, but it made our job easier ... It will be exciting to see } \\
& \text { what happens with our texts in the future (Source: blog post). }
\end{aligned}
$$

It seems clear that the challenges related to improving the article will potentially be very different depending on quality of the original article. This variation in quality increases the complexity in assessing the work of the students. Text revision becomes as important as new text production. The quoted student for instance removed a lot of the text in the article, thereby reducing the total size of the article.

This writing activity therefore also needs to be part of the assessment. Here as well we can see that the quoted student embraces the idea of a textbook project that never ends. The sentence "It will be exciting to see what happens with our texts in the future" indicates this. In this course the wiki work was not an assignment to be completed, handed to the teacher, and never seen nor used again. This was an assignment that resulted in something valuable that other students would continue to use. They knew that the wiki was going to be there for them in the future and that each semester, new groups of students would be contributing content. Likewise other wiki studies indicate an additional future horizon in the course: "The wikibook project let us produce our own learning product. And this product can be added and revised in the future. I like it!" (Lin \& Kelsey, 2009:163).

Having to remove text as part of a course assignment in a formal course was a new experience. Still, most of them experienced this as exciting. Another student wrote:

This was really exciting work. Both of us agreed upon writing and editing the article about "net societies" ... This was really fun. It's not every day one goes ahead and changes a piece of work that is considered finished. This was a way of working that I wish we could do in more courses (Source: blog post).

The student here reflects on the process and clearly sees the value of changing (and also removing) text in collaborative online environments. This student has done significant changes in the text, both in regard to the content and the structure of the article. Interestingly, the student experiences it as fun to change work that is considered finished. 
Some students even noted that this way of working made them get into the core of the subject in a faster way, even though it was difficult work. According to Matthew et al. (2009), wiki assignments are different from individual writing assignments because the students have to be aware of their peers' contributions. Students have to continually read their classmates' postings in order to avoid reposting information on the pages. In this way students invested more time and effort in learning the course content when they were trying to find new material to post (publish). This may possibly lead to a deeper understanding of the course content and enhanced retention of the material (Matthew et al., 2009).

Likewise, when students worked with the wiki assignments in the textbook project, they also had to compare and contrast the information they found on the Internet with the existing wiki content in order to be able to add meaningful content. New knowledge had to be built in the textbook version from 2008. In this way they were forced to read the existing material and try to improve it, in contrast to students in Matthew et al. (2009), who did their revision work within the same course period, while the editing process in this case study was done one year afterwards.

Interestingly, several students were skeptical about removing or changing text that last year's students had made. Some students found it almost rude to change others' work. One student wrote:

It was an interesting assignment to change an academic article already being out there.
It felt a bit strange and wrong rewriting something that was already published. But it
was very informative and I got to know a lot about children's use of computers that I
didn't know before, for instance how much time children in fact spend in front of the
computer screen (Source: blog post).

This student thinks it is odd and almost wrong to continue the development of somebody else's text. This is experienced as difficult even though the students did not know the contributors from last year. This is consistent with other findings where students disliked editing the work of other students (Lin \& Kelsey, 2009; Lund, 2008). It also seems to be academically challenging to change a text that someone else has considered finished. One student wrote:

\begin{abstract}
I think it was exciting to go in and edit something that others have made, it's not something one often does. I am used to writing texts from bottom, so going in and changing someone others texts was demanding. One wants it to be as good as possible, but it's not so easy to know where to begin. I didn't either feel competent enough to correct others work, I don't necessarily know more about the topic than the one who already has written about it. One thing is new hyperlinks and pictures, but going directly into the text and removing and adding was tough. But all in all, a very positive experience, and I can see the usefulness of the work. I hope this editorial work continues in the course, it would have been fun to see if somebody goes in and changes what I have written (Source: blog post).
\end{abstract}

The student's feeling of incompetence is here a challenge. This student thinks it tough to change the content of somebody else's work not knowing if the article becomes better. According to the student it seems to be much easier to do minor changes like adding pictures or hyperlinks than doing substantial changes. In another wiki project these in fact were the only kinds of edits that students did (Lund, 2008). Despite these challenges, the student embraces the idea of a project that continues year after year. Still, the student finds that it was a very useful experience. 


\section{Conclusion}

As already mentioned, radical transparency is part of a bigger movement related to Web 2.0. We seem to be moving towards a culture where we to a larger degree will share information with each other in a new transparent network economy (Benkler, 2006). Web 2.0 gives everybody an opportunity to contribute. In this way collaborative Internet projects in schools can be looked upon as a strengthening of democracy by potentially giving anyone a voice. A fundamental premise behind the textbook project was that student contributors were willing to publish their text openly on the net. With Web 2.0 it seems to be more and more natural for students to do this as they are already part of global communities on the Internet. Interestingly, most of them had participated in transparent social networks such as Facebook, but very few of them seem to have experiences with publishing academic work.

Nevertheless, this case study indicates several beneficial pedagogical consequences of working in a radical transparent course space. The awareness of the presence of "the others" outside the course seems to be experienced as motivating in a positive way by most students. According to Matthew et al. (2009), an important feature with the wiki is its ability to connect people. In the same way the textbook project has supported a learning environment where students can connect with each other and discuss different academic topics. But in addition, this specific course has introduced potential collaboration with unknown others ("Outsiders") as an extra transparency dimension. Today the physical limitations of the classroom have disappeared with the Internet. This gives teachers the opportunity to create new authentic and motivating learning activities where students can interact easily with people and environments outside the classroom and school institution. On the other hand this leads to a greater need for critical literacy. Students have to reflect upon questions such as: Who are the people communicating and collaborating with me on the Internet? How should I react to changes that others have done to my text?

Another big difference from ordinary text assignments is that the students had to try to improve a text made by students last year. This activity seemed to increase the feeling of participation in a collaborative project both with former and future students. An initial conclusion suggests that increased course availability may generate an experience of being part of the course history in a motivating way. Wiki work can be related to a new kind of transparent literacy where different text versions are saved, used, edited and rewritten in an open and visible environment. Here students can continue to work with the textbook after they have finished the course formally. Still, preliminary research indicates that this seldom happens (Ebner, Kickmeier-Rust \& Holzinger, 2008).

Moreover, an archive of former student work seems to facilitate the first phase of a formal learning process for some new students. When much of the former course material and student work is available, it may be easier to understand how to solve course assignments. Students can study the historical development of a specific article and its discussions. In this way the textbook project can be looked upon as a collective portfolio where students have easy access to and revision possibilities for all the articles the class has produced (Baltzersen \& Tolsby, 2008; Foti \& Ring, 2008). Negotiations of meaning through the common experiences of the participants will here be reified over time (Lave \& Wenger, 1991). The success of Wikipedia is now inspiring educators around the world to develop innovative didactical designs. Globally based wiki environments will probably be an important supplement to the closed and local 
learning management systems which today dominate higher education (Dalsgaard \& Paulsen, 2009). However, if we adjust the wiki to our existing pedagogical thinking, we risk transforming it into something familiar (Ruth \& Houghton, 2009).

If we on the other hand want to use global wiki environments in education it seems to be important to understand the different pedagogical implications of radical transparency. Radical transparency extends course space and course availability and seems to offer an epistemology very different from traditional learning environments in tertiary education. Consistent with Ruth and Houghton (2009), the pedagogical principles then seem to rely much more on community building and participatory involvement. Similarly, Scardamalia and Bereiter (2006) emphasise the importance of knowledge-creating competencies and collaborative learning. The ability to collaborate in these transparent global wiki environments may also be looked upon as an important new way to acquire this kind of competence. Students are brought out of the classroom and into a global learning community on the Internet. By letting outsiders connect with the classroom, the traditional distinction between formal and informal learning is also blurred (Rudd et al., 2006). Radical transparency may therefore be an important concept that can encourage educators to reflect on how we can move students and their work out of the traditional classroom.

The papers produced by undergraduate students are rarely considered good enough for public publishing, but this has not been the case with the textbook project. Here the student work continues to live on. In this way one could claim that wikis could be used within a research-based pedagogy (Laframboise \& Shea, 2009). This preliminary research also suggests that radical transparency can transform traditional pedagogy into more learning intensive experiences if the didactical design is carefully planned.

\section{References}

Aharony, N. (2009). The use of a wiki as an instructional tool: A qualitative investigation. Journal of Web Librarianship, 3(1), 35-53.

Alexander, B. (2006). Web 2.0: A new wave of innovation for teaching and learning? EDUCAUSE Review, 41(2), 33-34. http: / / www.educause.edu/ EDUCAUSE+Review / EDUCAUSEReview MagazineVolume41/Web20ANewWaveofInnovationforTe/158042

Augar, N., Raitman, R. \& Zhou, W. (2004). Teaching and learning online with wikis. In Beyond the comfort zone: Proceedings ASCILITE Perth 2004.

http: / / www.ascilite.org.au/conferences / perth04/ procs / augar.html

Baltzersen, R. K. \& Tolsby, H. (2008). En digital mappetenkning innenfor det wikipedianske klasserommet?: Noen refleksjoner rundt hva som kjennetegner et radikalt gjennomsiktig læringsmiljø. In M. Allern, \& K. S. Engelsen (Eds.), Mapper i digitale læringskontekstar erfaringar og perspektiv frå høgre utdanning. Tromsø: Noregsuniversitetet.

Benkler, Y. (2006). The wealth of networks: How social production transforms markets and freedom. New Haven, Conn.: Yale University Press.

Bennis, W. G., Goleman, D., O'Toole, J. \& Biederman, P. W. (2008). Transparency: How leaders create a culture of candor. San Francisco: Wiley.

Bruns, A. \& Humphreys, S. (2005). Wikis in teaching and assessment: The M/Cyclopedia project. San Diego, California: ACM.

Bryant, S., Forte, A. \& Bruckman, A. (2005). Becoming wikipedian: Transformation of participation in a collaborative online encyclopedia. In GROUP '05: Proceedings of the 2005 International ACM SIGGROUP Conference on Supporting Group Work, 1-10. 
Buckingham, D. (2007). Beyond technology: Children's learning in the age of digital culture. Cambridge: Polity.

Cuillier, D. \& Piotrowski, S. J. (2009). Internet information-seeking and its relation to support for access to government records. Government Information Quarterly, 26(3), 441-449.

Dalsgaard, C. \& Paulsen, M. F. (2009). Transparency in cooperative online education. International Review of Research in Open and Distance Learning, 10(3). http: / / www.irrodl.org/index.php/irrodl/article/download/671/1301

Dohn, N. B. (2009). Web 2.0: Inherent tensions and evident challenges for education. International Journal of Computer-Supported Collaborative Learning, 4(3), 343-363.

Ebner, M., Kickmeier-Rust, M. \& Holzinger, A. (2008). Utilizing wiki-systems in higher education classes: A chance for universal access? Universal Access in the Information Society, 7(4), 199-207.

Elgort, I., Smith, A. G. \& Toland, J. (2008). Is wiki an effective platform for group course work? Australasian Journal of Educational Technology, 24(2), 195-210. http: / / www.ascilite.org.au/ajet/ajet24/elgort.html

Forte, A. \& Bruckman, A. (2006). From wikipedia to the classroom: Exploring online publication and learning. ICLS '06: Proceedings of the 7th International Conference on Learning Sciences, 182188. [verified 13 Oct 2010] http:// www.andreaforte.net/ForteBruckmanFromWikipedia.pdf

Foti, S. \& Ring, G. L. (2008). From ePortfolios to iPortfolios: The find, refine, design, and bind model. Canadian Journal of Learning and Technology, 34(3). http: / / www.cjlt.ca/index.php/cjlt/article/viewArticle/506/237

Fung, A., Graham, M. \& Weil, D. (2007). Full disclosure: The perils and promise of transparency. Cambridge: Cambridge University Press.

Garsten, C. \& Montoya, M. L. de (2008). Transparency in a new global order: Unveiling organizational visions. Cheltenham: Edward Elgar.

Giles, J. (2005). Internet encyclopaedias go head to head. Nature, 438(7070), 900-901.

Goleman, D. (2010). Ecological intelligence: The coming age of radical transparency. London: Penguin Books Ltd.

Hansen, J. S. (2008). The availability and transparency of education data in California. Education Finance and Policy, 3(1), 41-57.

Heafner, T. L. \& Friedman, A. M. (2008). Wikis and constructivism in secondary social studies: Fostering a deeper understanding. Computers in the Schools, 25(3), 288-302.

Hoisl, B., Aigner, W. \& Miksch, S. (2007). Social rewarding in wiki systems - motivating the community. In Online Communities and Social Computing. Proceedings Second International Conference, OCSC, 362-371.

Johnson, S. H., Shelton, B. \& Wiley, D. (2008). Collecting, organizing, and managing resources for teaching educational games the wiki way. Innovate: Journal of Online Education, 4(2). http: / / www.innovateonline.info /index.php?view=article\&id=423

Jonsson, A. (2010). The use of transparency in the "interactive examination" for student teachers. Assessment in Education: Principles, Policy \& Practice, 17(2), 183-197.

Karimi, A. \& Song, H. S. Y. (2009). Where is the wiki in wiki? In Same places, different spaces. Proceedings ascilite Auckland 2009.

http:// www.ascilite.org.au/conferences/auckland09/procs/karimi.pdf 
Kelly, A. P. \& Aldeman, C. (2010). False fronts? Behind higher education's voluntary accountability systems. USA: American Enterprise Institute, Education Sector. [verified 13 Oct 2010] http: / / www.educationsector.org/publications / false-fronts-behind-higher-educationsvoluntary-accountability-systems

Kirkpatrick, D. (2010). The Facebook effect: The inside story of the company that is connecting the world. London: Virgin Books.

Kolbitsch, J. \& Maurer, H. (2006). The transformation of the web: how emerging communities shape the information we consume. Journal of Universal Computer Science, 12(2), 187-213.

Konieczny, P. (2007). Wikis and wikipedia as a teaching tool. International Journal of Instructional Technology and Distance Learning, 4(1). http:/ / itdl.org/journal/jan_07/article02.htm

LaFee, S. (2009). Transparency. School Administrator, 66(1), 10-15.

Laframboise, K. L. \& Shea, K. (2009). Developing understanding of research-based pedagogy with preservice teachers: An instrumental case study. Qualitative Report, 14(1), 105-128.

Lathrop, D. \& Ruma, L. (2010). Open government: Collaboration, transparency, and participation in practice. Sebastopol, CA: O'Reilly Media.

Lave, J. \& Wenger, E. (1991). Situated learning: Legitimate peripheral participation. Cambridge: Cambridge University Press.

Leuf, B. \& Cunningham, W. (2001). The wiki way: Quick collaboration on the web. Boston: AddisonWesley.

Lin, H. \& Kelsey, K. D. (2009). Building a networked environment in wikis: The evolving phases of collaborative learning in a wikibook project. Journal of Educational Computing Research, 40(2), 145-169.

Lund, A. (2008). Wikis: A collective approach to language production. ReCALL, 20(1), 35-54. [verified 13 Oct 2010] http: / journals.cambridge.org/action/displayFulltext? type $=1 \&$ fid $=1584904 \&$ jid $=$ REC \&volumeId $=20 \&$ issueId $=01 \&$ aid $=1584900$

Lundin, R. (2008). Teaching with wikis: Toward a networked pedagogy. Computers and Composition, 25(4), 432-448.

Ma, W. W. K. \& Yuen, A. H. K. (2008). News writing using wiki: Impacts on learning experience of student journalists. Educational Media International, 45(4), 295-309.

Mak, B. \& Coniam, D. (2008). Using wikis to enhance and develop writing skills among secondary school students in hong kong. System, 36(3), 437-455.

Matthew, K. I. \& Felvegi, E. (2009). Learning course content by creating a wiki. TechTrends: Linking Research and Practice to Improve Learning, 53(3), 67-73.

Matthew, K. I., Felvegi, E. \& Callaway, R. A. (2009). Wiki as a collaborative learning tool in a language arts methods class. Journal of Research on Technology in Education, 42(1), 51-72. http: / / www.eric.ed.gov/PDFS / EJ856933.pdf

Murugesan, S. (2007). Understanding Web 2.0. IT Professional, 9(4), 34-41.

Nordkvelle, Y. (2007). Digitale mapper i høyere utdanning: Omfang, bruk og trender for framtida. Tromsø: Norgesuniversitetet.

Nystrand, M. (1997). Opening dialogue: Understanding the dynamics of language and learning in the English classroom. New York: Teachers College Press.

O'Reilly, T. (2005). What is Web 2.0: Design patterns and business models for the next generation of software. [verified 26 Oct 2010] http:/ / oreilly.com/ web2/archive/what-is-web-20.html 
O'Shea, P., Baker, P. \& Kidd, J. (2008). Is higher education ready to switch to digital course materials? Let a thousand wikibooks bloom. Chronicle of Higher Education, 55(14), A29.

Owen, M., Grant, L., Sayers, S. \& Facer, K. (2006). Social software and learning. Bristol: Futurelab. http:/ / www.futurelab.org.uk/resources/documents/opening_education/Social_Software_report.pdf

Parker, K. R. \& Chao, J. T. (2007). Wiki as a teaching tool. Interdisciplinary Journal of Knowledge and Learning Objects, 3, 57-72. http: / / www.ijklo.org/Volume3 / IJKLOv3p057-072Parker284.pdf

Ravenscroft, A. (2009). Social software, web 2.0 and learning: Status and implications of an evolving paradigm. Journal of Computer Assisted Learning, 25(1), 1-5.

Ravid, G., Kalman, Y. M. \& Rafaeli, S. (2008). Wikibooks in higher education: Empowerment through online distributed collaboration. Computers in Human Behavior, 24(5), 1913-1928.

Richardson, W. (2009). Blogs, wikis, podcasts, and other powerful web tools for classrooms. Thousand Oaks, CA: Corwin Press.

Rudd, T., Sutch, D. \& Facer, K. (2006). Towards new learning networks. Bristol, UK: Futurelab. http:/ / www.futurelab.org.uk/resources/documents/opening_education/Learning_Networ ks_report.pdf

Ruth, A. \& Houghton, L. (2009). The wiki way of learning. Australasian Journal of Educational Technology, 25(2), 135-152. http:/ / www.ascilite.org.au/ajet/ajet25/ruth.html

Scardamalia, M. \& Bereiter, C. (2006). Knowledge building: Theory, pedagogy, and technology. In R. K. Sawyer (Ed.), Cambridge handbook of the learning sciences (pp. 97-118) Cambridge University Press.

Sheehy, G. (2008). The wiki as knowledge repository: Using a wiki in a community of practice to strengthen K-12 education. TechTrends: Linking Research and Practice to Improve Learning, 52(6), $55-60$.

Staley, D. J. (2009). Managing the platform: Higher education and the logic of wikinomics. EDUCAUSE Review, 44(1), 36-38. http: / / www.educause.edu/EDUCAUSE+Review / EDUCAUSEReviewMagazineVolume44/ManagingthePlatformHigherEduca/ 163579

Tapscott, D. \& Ticoll, D. (2003). The naked corporation: How the age of transparency will revolutionize business. New York: Free Press.

Trentin, G. (2009). Using a wiki to evaluate individual contribution to a collaborative learning project. Journal of Computer Assisted Learning, 25(1), 43-55.

Wheeler, S., Yeomans, P. \& Wheeler, D. (2008). The good, the bad and the wiki: Evaluating student-generated content for collaborative learning. British Journal of Educational Technology, 39(6), 987-995.

Yukawa, J. (2006). Co-reflection in online learning: Collaborative critical thinking as narrative. International Journal of Computer-Supported Collaborative Learning, 1(2), 203-228.

Zorko, V. (2009). Factors affecting the way students collaborate in a wiki for English language learning. Australasian Journal of Educational Technology, 25(5), 645-665. http:/ / www.ascilite.org.au/ajet/ajet25/zorko.html

Rolf K. Baltzersen, Associate Professor

Faculty of Education, Østfold University College, 1757 Halden, Norway

Email: rolf.k.baltzersen@hiof.no

Web: http: / / www.hiof.no/index.php?ID=3\&lang=eng 